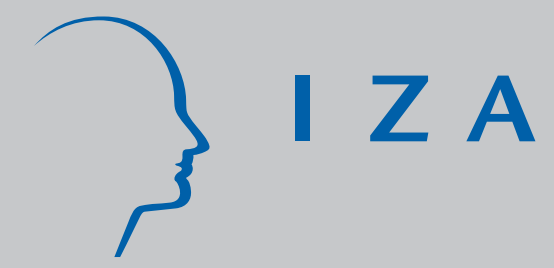

IZA DP No. 2219

Quantifying the Cost of Passive Smoking on Child Health: Evidence from Children's

Cotinine Samples

Paul Frijters

Michael A. Shields

Stephen Wheatley Price

J enny Williams

July 2006 


\title{
Quantifying the Cost of Passive Smoking on Child Health: Evidence from Children's Cotinine Samples
}

\author{
Paul Frijters \\ Queensland University of Technology \\ Michael A. Shields \\ University of Melbourne and IZA Bonn \\ Stephen Wheatley Price \\ University of Leicester \\ Jenny Williams \\ University of Melbourne
}

Discussion Paper No. 2219

May 2006

IZA

P.O. Box 7240

53072 Bonn

Germany

Phone: +49-228-3894-0

Fax: +49-228-3894-180

Email: iza@iza.org

\begin{abstract}
Any opinions expressed here are those of the author(s) and not those of the institute. Research disseminated by IZA may include views on policy, but the institute itself takes no institutional policy positions.

The Institute for the Study of Labor (IZA) in Bonn is a local and virtual international research center and a place of communication between science, politics and business. IZA is an independent nonprofit company supported by Deutsche Post World Net. The center is associated with the University of Bonn and offers a stimulating research environment through its research networks, research support, and visitors and doctoral programs. IZA engages in (i) original and internationally competitive research in all fields of labor economics, (ii) development of policy concepts, and (iii) dissemination of research results and concepts to the interested public.
\end{abstract}

IZA Discussion Papers often represent preliminary work and are circulated to encourage discussion. Citation of such a paper should account for its provisional character. A revised version may be available directly from the author. 


\title{
ABSTRACT \\ Quantifying the Cost of Passive Smoking on Child Health: Evidence from Children's Cotinine Samples ${ }^{*}$
}

\begin{abstract}
Passive smoking is a major public health issue. This paper documents the main risk factors that determine children's exposure to passive smoke, and then uses econometric techniques to provide a new economic quantification of the impact of this exposure on child health. Such information is valuable to policy-makers when deciding upon the amount of resources to direct towards the problem of passive smoking. One of our main contributions is the use of a large nationally representative sample of children drawn from the Health Survey for England, for whom we match parental and household smoking and demographic characteristics. We also utilise an objective measure of children's exposure, namely, the level of cotinine - a metabolite of nicotine - in their saliva. We find that both parental and child carer smoking behaviour, as well as area deprivation, are major risk factors in determining children's exposure to passive smoke. Accounting for the potential measurement error in cotinine in our estimations, we have calculated that for a child who is exposed to a high number of passive smoking risk factors, the shadow price or income-equivalence of such exposure is $£ 16,000$ (US\$30,000) per year. A further policy-related result is that comprehensively controlling for child passive smoking does not explain the observed gradient between household income and child health.
\end{abstract}

JEL Classification: D1, I1

Keywords: passive smoking, child health, parental smoking, cotinine, income

Corresponding author:

Michael A. Shields

Department of Economics

University of Melbourne

Australia 3010

E-mail: mshields@unimelb.edu.au

\footnotetext{
* We are grateful to John Freebairn and Andrew Oswald for useful comments and suggestions. The Health Surveys for England are used with the permission of the depositors (the Joint Survey Unit of the National Centre for Social Research and the Department of Epidemiology and Public Health at University College London) and the supplier (the Data Archive at the University of Essex). The usual disclaimer applies.
} 


\section{Introduction}

Passive smoking, also referred to as second-hand or environmental smoke, is a significant world-wide public health issue (EPA 1992, 1997; SCOTH 1998, 2004; WHO, 1999; US Surgeon General, 2006). Passive smoke consists of the combination of smoke from a burning cigarette and that exhaled by a smoker. It contains over 4,000 different chemical compounds, at least 40 of which are known to cause cancer, and is classified as Class A (known human) carcinogen by the US Environmental Protection Agency (EPA, 1992; ASH, 2005). Among children, exposure to second-hand tobacco smoke is most often inadvertent since it largely occurs within the home environment. Infants and children are particularly vulnerable to the effects of passive smoking because their lungs and immune systems are still developing (ASH, 2005; US Surgeon General, 2006). According to WHO (1999), nearly half of the 700 million children in the world are exposed to passive smoking. In the US, about 20\% of children are reported to regularly breathe in second-hand smoke at home (US Surgeon General, 2006). While the number of children exposed to passive smoke in the home in Britain (over 40\% in 1998) is generally on a downward trend, following the decline in adult tobacco consumption, those who are still living with a smoker have experienced little change in the intensity of their exposure (Jarvis et al., 2000).

Passive smoking is strongly linked to adverse child health outcomes (SCOTH, 1998, 2004; WHO, 1999, US Surgeon General, 2006). In particular, available medical evidence suggests that passive smoking leads to lower birth weight (Windham et al., 1999) and is a primary factor associated with sudden infant death syndrome. In childhood, environmental tobacco smoke exposure has been linked to decreases in lung function (Mannino et al., 2001; 2002), an increased incidence of middle ear disease (Adair-Bischoff and Sauve, 1998), recurrent ear infections (Lieu and Feinstein, 2002) and bacterial meningitis (Iles et al., 2001) as well as serious respiratory problems such as an increased risk of pneumonia, bronchitis and asthmatic attacks (Burr et al., 1999; Cook and Strachan, 1999; Gilliland et al., 2001; Li et al., 1999; Li and Peters, 2001). More recent studies confirm these findings (SCOTH, 2004) and have shown that childhood exposure to tobacco smoke is also associated with school absence due to respiratory illness (Gilliland et al., 2003), long-term sickness absence from work (Eriksen, 2004) and other indicators of poor health in adulthood (Graham and Power, 2004).

In the economic model of health developed by Grossman (1972), parents use resources, such as income and time, to invest in their children's health. Several recent papers (notably Case et al., 2002 and Currie and Stabile, 2004) have documented an empirically robust relationship between household income and child health (see also Currie et al., 2004 and Burgess et al., 
2004; and Cameron and Williams, 2005; for evidence from Britain and Indonesia, respectively) and have sought to identify which of the array of potential investments are important in accounting for the observed gradient. However, factors such as dietary intake (Currie et al., 2004; Cameron and Williams, 2005) have provided only a partial explanation of why the health of children is worse in poorer households. Since passive smoking is known to be three times more likely amongst children from lower socio-economic households, as compared to children living in professional households (ASH, 2002), it may have a significant role to play in explaining the child health / household income nexus. ${ }^{1}$

In this paper we aim to contribute to the broad understanding of the factors affecting children's exposure to passive smoking, and the effects of such exposure on child health. Our particular objective is to quantify the size of these factors and effects using a large nationally representative sample of children. One key advantage of our data, drawn from the Health Survey for England (HSE), is that it contains an objective measure of children's exposure to passive smoke. This measure is the level of cotinine in their saliva, where the saliva is collected by a qualified nurse using a swab. Cotinine is the major metabolite of nicotine and is a widely used, sensitive and specific, biomarker of active smoking and short term exposure to second-hand smoke (EPA, 1997, chapter 3). Recently it has been shown to be highly correlated with compounds known to be adverse risk factors for health (SCOTH, 2004), such as the potent tobacco carcinogen NNK (Hecht et al., 2001).

Two recent papers by Adda and Cornaglia (2006a, 2006b) have also used cotinine levels as a measure of passive smoking, for a sample of US adults, to explore the impact of tobacco taxes and smoking bans in public places. Using US state level variation in tobacco taxes, Adda and Cornaglia (2006a) provide evidence that such taxes lead adults to extract more nicotine per cigarette. $^{2}$ More directly relevant to this study are the results of Adda and Cornaglia (2006b) who find some evidence that smoking bans in recreational public places may lead to increased exposure to passive smoke for non-smokers. This might happen because smokers react by shifting their cigarette consumption to private places such as the home, which could lead to higher levels of child passive smoking. Our study therefore can be seen as complementing Adda

\footnotetext{
${ }^{1}$ Case et al. (2002) include an indicator of whether someone in the household smokes in their final model (see Table 11, p. 1130). The coefficient is positive and highly significant but its inclusion fails to reduce the income gradient substantially. Our measure of children's exposure to passive smoking is more objective, and we are able to model its determinants (and control for potential measurement error) enabling us to quantify the effect more precisely, in our data.

${ }^{2}$ Note that in England there is no regional variation in tobacco taxes, and a national ban on smoking in pubs/restaurants will come into force in July 2007.
} 
and Cornaglia's (2006b) study by directly investigating the relationship between parental smoking and child health.

An important empirical issue faced when modelling the health effects of passive smoking is unobserved differences in the way children's bodies take up and metabolise the nicotine from passive smoking. For example, two siblings exposed to the same amount of passive smoke may register different levels of cotinine and therefore appear to have different levels of exposure. In this paper, we tackle this measurement error problem by using an instrumental variable strategy in order to obtain consistent estimates of the impact of passive smoking on child health. Our results confirm that parental smoking and the smoking behaviour of other household members are powerful predictors of children's intake of passive smoke. Moreover, higher levels of passive smoking are significantly associated with worse child health, but interestingly this does not explain away the estimated gradient between household income and child health.

Using our estimation results, we are able to provide new quantification of the cost of children's passive smoking. We calculate that, in order to offset the negative health effects of a child living with a very high number of passive smoking risk factors, household income would have to be raised by around $£ 16,000$ (US\$30,000) per year. Our results also suggest some good news for policy makers. We find the most important risk factors, namely the smoking behaviour of parents, others in the household and child carers, are all to an extent amenable to public policy aimed at reducing children's exposure to passive smoking.

The remainder of the paper is organized as follows. In Section 2 we describe our data, define our measures and highlight the principle features of our sample. Our econometric modelling strategy is described in Section 3 and the results are discussed in Section 4. Section 5 concludes the paper.

\section{Data and Sample Description}

\subsection{Data Source}

We use data from the Health Surveys of England (HSEs), which was commissioned by the UK's Department of Health and has been conducted by the Joint Health Surveys Unit of the National Centre for Social Research and the Department of Epidemiology and Public Health, Royal Free and University College London. Beginning in 1992, each HSE is a nationally representative survey of private households in England, providing an annual cross-section of the population with which to monitor trends in the nation's health. It uses the Postcode Address File as a sampling frame. The average response rate of households at selected addresses is $75 \%$, within which successful interviews are conducted with $90 \%$ of individuals. A sample of around 16,000 
individuals is typically obtained. Many individual, household and demographic characteristics are recorded in the HSE as well as detailed information on a range of self-reported and objectively assessed health indicators.

From 1995 onwards data on a maximum of two (randomly selected) children, aged 2-15, has also been obtained from the sampled households (see Sprosten and Primatesta, 2003, for further details). Information is obtained directly from children between the ages of 13 and 15, with parental consent, whilst questions about younger children are asked to the parents with the child present. For each household, with up to two sampled children, we have matched information on one or both parents, based on the adult responses to the survey. Crucially, we are able to exactly identify the fathers and mothers for $99.4 \%$ of children. We can also determine whether missing information on one parent represents a permanent absence from the household, a temporary absence at the time of the interview (e.g. working away from the household) or an incomplete interview response.

The HSE data are collected by a combination of face-to-face interviews, self-completion questionnaires and medical examinations undertaken by a qualified nurse. If consent is given by the parent, blood and saliva samples are taken from all children aged 4 years and older. Importantly, the amount of cotinine in children's saliva, which provides the basis of our measure of passive smoking, was only collected in the 1997, 1998, 2001 and 2002 HSEs. ${ }^{3}$ The detailed information obtained on the smoking behaviour of all household members is also of particular interest to this study. Pooling these four years of data gives a sample of 9,401 children aged 415. However, in this paper we use a sample of 6,679 (71\%) of these children (living in 4,682 households), for which we have a valid measure of the amount of cotinine in their saliva. ${ }^{4}$

\subsection{Sample Characteristics}

The average age of the sample of children is 9.65 years, with $50.1 \%$ being male and $10.1 \%$ having an ethnic minority background (Black 2.3\%; South Asian 4.6\%; other ethnic minority $3.1 \%$ ). Some $25 \%$ of these children live in a household with no adult male whilst just $2.2 \%$ live

\footnotetext{
${ }^{3}$ See Currie et al. (2004) for a detailed investigation in the family income / child health gradient, and in particular whether or not the steepness of the gradient increases with child age, using the matched HSE parent-child data for the years 1997 to 2002.

${ }^{4}$ In this paper we do not attempt to model this selection. However, information on child cotinine is missing either because (i) a nurse was not able to take the required saliva test, either because he/she was unable to organise an interview with the household, or (ii) conditional on being able to interview, parents did not give permission to the nurse to take a saliva sample from their child or children. It is difficult to a priori sign any potential bias for this selection. For example, if parents who are heavy smokers also have children in bad health (caused by passive smoking), and are also more likely to refuse permission for a nurse to take a child saliva sample, then this might lead us to underestimate the affect of parental smoking on child health. However, parental smoking was not found to be a significant predictor of this selection when we estimated a binary probit model.
} 
without an adult female in the household. Nearly $14 \%$ of all fathers, and $12.4 \%$ of all mothers, have a degree level qualification whilst around $20 \%$ of both mothers and fathers achieved their highest qualification at A-level or equivalent. Unemployment rates for both mothers and fathers in our sample are very low at $2.4 \%$, whilst non-participation rates are, not surprisingly, much higher for mothers (25.1\%) than fathers (5.6\%).

The majority of our sample live in suburban areas (60.5\%), whilst $15 \%$ are located in urban areas and $24.4 \%$ live in a rural setting. Our sample is disproportionately drawn from the 1998 (35.7\%) and 2001 (29.5\%) HSEs, where the nationally representative sample is roughly double that obtained in the 1997 (19.5\%) and 2002 (15.3\%) HSEs. The latter two surveys focus half their sample on just children. Unfortunately, these booster samples are unable to be utilized for our purposes as no information on parents, especially their smoking behaviour, is obtained.

\subsection{Measuring Child Passive Smoking}

Of primary interest in this paper is the result of tests carried out on the saliva samples (collected by qualified nurses) obtained from children aged 4-15 years old, and their parents. One of these tests provides a measure of the level of cotinine present in the person's saliva. Cotinine is the most widely accepted biomarker of exposure to tobacco smoke (EPA 1992, 1997; SCOTH 1998, 2004). Cotinine levels are accurately measured by gas chromatography, radioimmunoassay, or high pressure liquid chromatography in concentrations above $1 \mathrm{ng} / \mathrm{mL} .^{5}$ While nicotine has a half life of about 2 hours in the blood, the half life of cotinine is approximately 20 hours for smokers but is longer for non-smokers, especially children with exposure to second-hand smoke. The half life of cotinine makes it a good indicator of environmental tobacco smoke exposure over the previous day or two (EPA, 1997). Cotinine, nonetheless, shows considerable inter-subject variability in controlled nicotine exposure studies due to individual differences in uptake, distribution, metabolism and elimination. We tackle this potential measurement error problem in our econometric approach. The average cotinine value for the sample is $7.31 \mathrm{ng} / \mathrm{ml}$, with a standard deviation of 35.68 . The minimum value is zero and the maximum is close to $600 \mathrm{ng} / \mathrm{ml}$. The distribution of cotinine is right-skewed with around $60 \%$ of children having less than $1 \mathrm{ng} / \mathrm{ml}$ of cotinine in their saliva.

\footnotetext{
${ }^{5}$ Plant sources other than tobacco (such as eggplant, tomato and green pepper) have been suggested as sources of cotinine, although the average contribution of dietary intake to measured cotinine levels are expected to be below 1 $\mathrm{ng} / \mathrm{mL}$.
} 


\subsection{Passive Smoking and Parental Smoking Behaviour}

Over $30 \%$ of the children in our sample live with a mother who smokes regularly whereas only $19.2 \%$ live with a father who is a smoker. Nearly $40 \%$ of these children living in England, whose parents respond to the smoking behaviour questions, live with at least one parent who is a smoker whilst 9.6\% live with two smoking parents. Amongst the parents in our sample the average cotinine levels for men is $99.4 \mathrm{ng} / \mathrm{mL}$ and for women is $95.2 \mathrm{ng} / \mathrm{ml}$. However, the average levels for those who report being smokers is far higher than for non-smokers. Male (female) smokers in our sample are found to have average cotinine levels of $340.0(300.9) \mathrm{ng} / \mathrm{ml}$ whilst male (female) non-smokers average levels are just 16.1 (6.6) ng/ml.

The impact on the amount of cotinine present in a child's saliva from living with parents who smoke be can seen from the difference between the average level of a child living with two nonsmoking parents $(2.50 \mathrm{ng} / \mathrm{ml})$ and one living with parents who both smoke $(13.2 \mathrm{ng} / \mathrm{ml})$. Interestingly, the effect of living with a mother who smokes $(14.1 \mathrm{ng} / \mathrm{ml})$ is much greater than that of living with a father who smokes $(4.7 \mathrm{ng} / \mathrm{ml})$. This reflects the fact that mothers are typically the principle carer of children and hence children have a greater exposure to the smoking behaviour of the mother than the father (Cook et al., 1994). Of course for some of these children, it is their own smoking behaviour which, at least in part, influences the reported cotinine levels. We can explore this in the older age group of children (12-15 years old) who are asked detailed questions about their own smoking behaviour. For those children who do not live with a parent who smokes, those who report not to smoke themselves have an average cotinine level of 3.6ng/ml. Amongst the children with non-smoking parents, the impact of their own smoking is to raise their cotinine levels, on average, to $88.63 \mathrm{ng} / \mathrm{ml}$. Children who smoke and who live with two parents who also smoke have an average cotinine levels of 194.2ng/ml.

\subsection{Passive Smoking and Household Income}

The measure of income that we use in this paper is the current total pre-tax annual family (living in the same household) income, which is provided in 31 bands in the data, ranging from less than $£ 520$ to more than $£ 150,000$. These data are converted to a pseudo-continuous measure by taking the midpoint of the band that the household reports their income to fall within and then deflating this income (to 2000 prices) using the UK average earnings index according to the month in which the interview was conducted (see Currie et al., 2004, for more details). The average household pre-tax annual income in the sample is just under $£ 29,000$, and the sample is representatively spread throughout the English regions. Note that household income is missing 
for just under $10 \%$ of our sample, and in the econometric analysis we present later in the paper we include a control for these missing cases.

In Figure 1 we graph the average cotinine level, amongst all children, 4-11 year old children and 12-15 year old children, against household income. There is a clear negative relationship, between cotinine and income, with children living in lower income households recording approximately four times the level of cotinine in their saliva than children from the highest income households. The gradient is most pronounced amongst households whose income is below $£ 30,000$ and for the older children, who are much more likely to be smokers themselves. This suggest that differences in the exposure to passive smoke might be important in explaining the remaining (after controlling for a wide-range of individual, parental and household characteristics) child health / household income gradient found, for example, in Case et al. (2002) and Currie et al. (2006).

\subsection{Passive Smoking and Child Health}

Whereas the medical literature highlighted in Section 1 has typically focused on the effect of passive smoking on a given illness or health condition, our measure of child health is more general in nature and comes from a question asked to parents about the general health of their child (or asked to the children themselves in the case of 13-15 year olds). The possible responses are on a five-point ordinal scale, and very similar measures of child health have been the focus of a number of recent papers exploring the socio-economic gradient in child health (see, for example, Case et al., 2002; Currie and Stabile, 2003; Currie et al., 2004; Cameron and Williams, 2005). Such self-reported measures of general health status have been shown to be strong predictors of future functional mobility and mortality for adults (see, for example, Idler and Angel, 1990; Idler and Kasl, 1995; Idler and Benysmini, 1997; van Doorslaer and Gerdtham, 2003).

The percentage of children in each response category in our sample is shown in parentheses below:

1. Very Good (56.1\%)

2. Good (37.5\%)

3. Fair (5.8\%)

4. Bad (0.5\%)

5. Very Bad (0.3\%) 
It can clearly be seen that the vast majority of children in England are reported to be in Very Good or Good health (93.6\%). We should note that these percentages are also nearly identical to those found for the total sample of 9,401 children before we drop the children for whom we do not observe a valid cotinine value. This suggests that there is not an initial selection on child health, in that it is not parents of children in poor health that are more or less likely to refuse the nurse interview or the collection of a saliva sample from their child.

Figure 2 graphs the percentage of children reported as having fair, poor or very poor health against their average cotinine level. We show the relationship for all children, and separately for 4-11 year and 12-15 year old children. Noting that higher numbers indicate worse health, Figure 2 indicates a negative relationship between the health of children and the level of cotinine in their saliva. That is, children with higher levels of cotinine are more likely to be reported as having only fair, bad or very bad health. For example, only about $4 \%$ of children with less than $0.1 \mathrm{ng} / \mathrm{ml}$ of cotinine are reported to be in less than good health compared to $12 \%$ of children with $10+\mathrm{ng} / \mathrm{ml}$. Interestingly, there are no substantial differences across the two broad age groups. This also provides some reassurance about the consistency of the responses to these questions in the data, given that parents provide the health status information for younger children whereas the 12-15 year old children are reporting their own health levels.

In the econometric analyses that follow, due to the small percentage of children in England classed as being in "Very Bad" health, we collapse the responses "Bad" and "Very Bad" into one category (4 = Bad or Very Bad), providing us with a four-point ordinal indicator of selfassessed general health status which we use as our measure of health.

\section{Econometric Approach}

The goal of this paper is to establish the quantitative effect of passive smoking on child health and to determine the extent to which exposure to passive smoking accounts for the relationship between household income and child health observed in the recent literature. Accordingly, we model child health status as follows:

$$
\begin{gathered}
C H^{*}{ }_{i h}=X_{\text {ih }} \beta+\ln y_{h} \alpha+\ln \left(P S_{i h}\right) \gamma+v_{i h} \\
C H=k--->\lambda_{\mathrm{k}-1}<C H^{*}<=\lambda_{\mathrm{k}}
\end{gathered}
$$

where $\mathrm{CH}_{\text {ih }}^{*}$ is the unobserved latent health of child $i$ living in household $h, \mathrm{CH}_{i h}$ is observed child health, $X_{i h}$ is a vector of observable child and household characteristics, $y_{h}$ is household 
income that is constant across all children in the same household $h, P S_{i h}$ is child-specific exposure to passive smoke and $v_{i h}$ is an error term. We presume the error term to be normally distributed. Since we observe child health in ordinal categories, we estimate this model using an ordered probit regression. To account for the potential correlation across siblings in the unobserved components of child, we allow the covariance matrix to be clustered on the household.

We wish to use observed cotinine levels as an indicator of passive smoking but we face two econometric problems. One is that, while cotinine is the most widely accepted biomarker for exposure to nicotine over a period of 1 or 2 days, individuals do differ in their uptake, distribution, metabolism and elimination of nicotine. Consequently, two siblings living in the same house with the same exposure to nicotine may have different levels of cotinine present in their saliva. We should thus think of observed cotinine levels as a noisy estimate of the actual level of passive smoking. The second complication is that the machine measuring cotinine in the saliva cannot pick up concentrations lower than 0.1 parts per million. It turns out that $16 \%$ of the sample has left-censored cotinine values. Considering both problems, the observed value of cotinine is thus related to latent cotinine values:

$$
\begin{aligned}
\ln \left(\text { cotinine }_{i h}^{*}\right) & =\ln \left(P S_{i h}\right)+\varepsilon_{h}+\varepsilon_{i h}=X_{i h} \delta_{0}+\ln y_{h} \delta_{1}+Z_{i h} \delta_{2}+\varepsilon_{h}+\varepsilon_{i h} \\
\operatorname{cotinine}_{i h} & =I_{\text {cotine } \left._{i h}^{*}\right)>0.1} \text { cotinine }_{i h}^{*}
\end{aligned}
$$

Where cotinine $_{i h}$ is the observed level of cotinine as recorded in our data, and cotinine ${ }^{*}$ in is the latent level of cotinine, which is observed as left censored at 0.1 parts per million. Here, there are two measurement error components, one specific to the household $h$, and another to the individual $i$, satisfy:

$$
\begin{aligned}
& \varepsilon_{\mathrm{h}} \sim \operatorname{iid~} \mathrm{N}\left(0, \sigma_{\varepsilon 1}^{2}\right) \\
& \varepsilon_{\mathrm{hi}} \sim \operatorname{iid~} \mathrm{N}\left(0, \sigma_{\varepsilon 2}^{2}\right)
\end{aligned}
$$

which means we estimate a Tobit model with random effects using maximum likelihood. The correlation in cotinine levels of children from the same family, due to unobserved household factors, is accounted for using household random effects. In this first stage regression we can comprehensively determine the factors that influence passive smoking and their relative 
contribution. We are able to do this given the wide ranging information on child, parental, grandparental and carer smoking behaviour available in the HSE.

Due to the fact that cotinine levels are likely to be a noisy measure of passive smoking, direct estimation of equation 1 would result in a biased (towards zero) and inconsistent estimate of $\gamma$. In order to obtain a consistent estimate, we replace the actual values of (log) cotinine with the predicted value using equation 2. Identification of the effect of passive smoking relies on the availability of suitable instruments. These are variables that determine the true cotinine levels, are not correlated with the measurement error in cotinine, and do not directly effect child health. These instruments, $Z_{i h}$, comprise a comprehensive set of measures of smoking by parents, grandparents and carers. We think it reasonable to assume that these variables exclusively affect child's health through their exposure to passive smoking and that they are also uncorrelated with the source of the measurement error, which is the way children metabolise nicotine. For this to be a valid procedure, it also has to be the case that the instruments $Z_{i h}$ are uncorrelated with the unobserved health characteristics in $v_{i h}$. We will test this assumption in the following section.

The results from the first-stage estimation give a predicted log cotinine value which is an unbiased linear prediction of passive smoking values that is unrelated to the measurement error and the error term in the child health equation. The strength of the measurement error problem can be ascertained by comparing the coefficient of cotinine values when these values are directly included in the child health equation versus that of the predicted cotinine values.

A minor econometric issue also may arise if the presence of cotinine in the child's saliva may be due to their own smoking. Own smoking is not what we have in mind when we think of passive smoking, and we therefore need to subtract the effect of own smoking from our predicted measure to arrive at predicted passive smoking. Furthermore, second-hand smoke has a different chemical composition than smoke inhaled directly into the lungs from a cigarette and these different chemical compositions may have different health consequences. Therefore we allow own smoking to have a direct effect on child's health which is independent of the predicted cotinine level, This is done by allowing predicted environmental tobacco smoke exposure and the child's own smoking to enter separately into the model for child health.

\section{Results}

\subsection{Model of Passive Smoking, Goodness-of-Fit and Instrument Power}

The results from estimating first stage household random effects tobit models of the measured (log) cotinine levels for all children aged 4-15, and separately for children aged 4-11 and 12-15, are provided in Table 1 . The explanatory variables are the same for each of the age groups, with 
the exception that children's own smoking is not controlled for in the model for 4-11 year olds. This is because we exclude the very few children who smoke under the age of 12 from our sample. The results, with respect to passive smoking, are not sensitive to the exclusion of these observations.

The key sources of passive smoking faced by children that we control in our model are the following set of parental, grandparent and household smoking indicators:

(i) Mothers' and fathers' own smoking behaviour: whether they are a current smoker, the amount they currently smoke, and their reported cotinine value from a saliva sample;

(ii) Whether any of the child's grandparents smoked (when their parents were children themselves, to attempt to capture any current interaction between grandparents and grandchildren);

(iii) Indicators for whether there are any other smokers in the household (for example, siblings or other relatives); and,

(iv) A variable signifying whether there is a child carer in the household who currently smokes.

We assume that these measures of parental and other household smoking only impacts on child health through their role in increasing the amount of passive smoke that a child is subjected. In addition, the model for exposure to passive smoking controls for a combination of child, parental, household and environmental characteristics. The characteristics of the children themselves are age, gender and ethnicity dummies and indicators of the child's own smoking behaviour. We also include our household income measure (and an indicator if this variable is missing) and dummy variables for the year of the HSE in which the interview took place. We also control for a number of other parental socio-economic characteristics, namely, the age of each parent, their highest educational qualification levels, their employment status, and whether either has a limiting long-term illness. ${ }^{6}$

Finally, we include a number of indicators to capture the external environment that the child is exposed to. These are whether the household is in a suburban or a rural location (relative to urban), dummies for broad English region of residence, and a general Index of Multiple Deprivation which is disaggregated to the district health authority level (DHA). The children in the sample live in 100 different DHAs, and the index is observed to range from 8 to 58

\footnotetext{
${ }^{6}$ We additionally include indicators for missing information on the parental smoking measures, and control for whether the mother or father is absent from the household, or whether they are in the household but failed to respond to the questionnaire.
} 
(increasing in deprivation). ${ }^{7}$ Lastly we control for parental drinking behaviour (whether the mother or father drinks regularly), which may be associated with children's exposure to passive smoking.

As a measure of the goodness-of-fit of the models we report the proportion of the total variation in log cotinine explained by the explanatory variables, and the proportion of the unexplained variation captured by the household random effects term. For the sample of all children aged $4-15$, the explanatory variables explain $49.2 \%$ of the total variation in log cotinine with the household term capturing 39.5\% of the total unexplained variation. The explanatory variables do better for the younger (49.9\%) than the older (41.2\%) age group, and the household correlation also captures more of the unexplained variation in cotinine for children aged 4-11 (48.2\%) than for those aged 12-15 (28.2\%). The latter finding might be explained by older siblings having greater autonomy from their parent's than younger children. When we estimate the model for the full sample (aged 4-15) including only child characteristics (e.g. age, gender and ethnicity) the proportion of the total variation in cotinine explained by these characteristics is $13.9 \%$. This increases to $21.8 \%$ when we additionally include children's own smoking behaviour controls, and increases further to $48.8 \%$ when we add in the parental and household smoking 'instruments'. The goodness-of-fit finally increases to $49.2 \%$ when we add the group of explanatory variables relating to parental characteristics (e.g. age, education, employment status) and location of residence. It is therefore clear that the final models we use are very strong predictors of the amount of cotinine in a child's saliva. Importantly, the calculations also demonstrate a strong correlation between the instrument set and cotinine, so weak instruments are unlikely to be an issue in these data.

\subsection{Passive Smoking Risk Factors}

The results in Table 1 show that boys have significantly lower levels of cotinine than girls but only in the younger age group. Despite the presence of the wide range of for own, parental and household smoking characteristics, children from Black or Asian backgrounds are found to have significantly lower levels of cotinine in their saliva samples. It is interesting to note that household income is a significant predictor of passive smoking for each of the age groups, even taking into account the controls for parental smoking, education and employment status.

\footnotetext{
${ }^{7}$ The Index of Multiple Deprivation (IMD) produced by the UK government, is calculated at the District Health Authority level (of which there are about 100 in the UK). The IMD is constructed as a weighted average of the six domains of deprivation (Department for the Environment, Transport and the Regions, 2000). These domains are (with their weights in brackets) low income (25\%), employment (25\%), education and training (15\%), poor health and disability (15\%), poor housing (10\%) and poor geographical access to services $(10 \%)$. See Shields and Wheatley Price (2005) for additional information.
} 
However, the coefficient on the log of household income is three times bigger for older than younger children, suggesting that the socio-economic gradient in passive smoking increases with child age. Finally, the quantity of cotinine measured in a child's saliva increases with the age of the child (coefficients not shown in Table 4).

As expected, children's own smoking has the largest single role in explaining cotinine levels, but it is also the case that parent's smoking behaviour is very important. It is clear from Table 1 that the parental and household smoking 'instruments' are highly significant predictors of child passive smoking. An interesting finding is that the influence of mother's smoking is approximately $50 \%$ greater than that of father's for children aged $4-11$, and $100 \%$ greater for teenagers. This suggests that children spend a greater amount of time with their mother than their father. It could also suggest that father's do more of their smoking consumption away from the home relative to mother's. Importantly, even after controlling for the smoking behaviour of parents, the level of cotinine in each of the parent's saliva is significantly and positively related to the measured cotinine level in their child's saliva, suggestive of either under-reporting of average cigarette consumption by the parents or the presence of other common external sources of passive smoking. The presence of another household member who smokes, or a child carer who smokes, also significantly increases cotinine levels in roughly the same magnitude as does the presence of a smoking father. However, having another household member who is a nonsmoker has a small protective or deterrent effect as it is significantly associated with lower levels of passive smoking. A family history of smoking, by paternal and maternal grandparents, is found to have no significant influence on the child's cotinine level in the presence of controls for parental smoking behaviour.

The inclusion of the additional parental characteristics yields some additional insights into child passive smoking. Whilst only statistically significant at the $10 \%$ level, there is evidence that passive smoking is higher for children living with a lone-mother than for children living with both parents. While the age or employment status of parents does not appear to explain passive smoking exposure, parental education does play an important role. Even after controlling for parental smoking behaviour and household income, a child of more educated parents has a significantly lower exposure to passive smoke, with the mother's education having a larger 'protective' role than the father's education. One explanation for this is that more educated parents have greater knowledge about the damage that passive smoking can inflict on their child's health, thus making them less likely to smoke (or let others smoke) in the presence of their child. 
Exposure to passive smoking in the external environmental is also evident from our results. However, only for the younger age groups do we find that living in a rural location is associated with lower levels of passive smoking than in city locations. We do find some evidence that children living in areas with a higher value of the Index of Multiple Deprivation have significantly increased cotinine levels. This indicates that children living in more deprived areas have a greater exposure to passive smoking, possibly from a greater interaction with neighbours and parents of school friends who smoke, than children living in less deprived areas. We also find that father's who drink regularly expose their children to more passive smoking, perhaps because they take their children to the pub more frequently or invite other drinkers (who are also smokers) to the home more regularly.

\subsection{Passive Smoking and Child Health}

In Table 2 we report the results from estimating ordered probit models of general health status for the whole sample of children aged 4-15 using a set of controls very similar to other recent studies of child health (see, for example, Case et al., 2002 and Currie et al., 2004). Since our primary motivation is to quantify the effect of passive smoking on child health, and a secondary interest is in examining whether passive smoking can help explain the observed gradient between family income and child health, we report three sets of results. In Model 1 we estimate a standard model of the determinants of child health, excluding any measure of passive smoking, to provide a comparison point for previous studies of child health and to obtain a benchmark estimate of the income coefficient. Model 2 then additionally includes the raw passive smoking measure - cotinine levels as reported in the data. Finally, in Model 3, we replace the raw measure with our predicted (instrumented) measure of the 'true' cotinine level. In Table 3 we additionally report the results of estimating Model 3 separately for the two broad age groups. In all models we control for the full set of child, parental, household and external environmental characteristics contained in the log cotinine models discussed in Section 4.2, but exclude the parental and household smoking behaviour 'instruments'.

For the sake of brevity we will not discuss the estimated coefficients from the general determinants of child health models except to note that they are consistent with previous work in the area. In particular, there is now a well documented positive gradient between family income and child health (see, for example, Case et al., 2002, for US evidence; Currie and Stabile, 2004 for Canadian evidence; Currie et al., 2004, for UK evidence and Cameron and Williams, 2006 for Indonesian evidence). As previously noted one proposed, but not yet directly tested hypothesis, is that this gradient might be explained by children from poorer families having a 
higher likelihood of smoking themselves and also being more frequently exposed to passive smoking.

In all three models in Table 2 children's own smoking is found to be significantly detrimental to health. Importantly, we find evidence that passive smoking also leads to a significant reduction in the probability of being in good health. The size of this effect is doubled when we include the predicted cotinine values compared to when the raw values are used, which is consistent with the presence of measurement error causing attenuation bias of the maximum likelihood estimator. We have calculated that a one-log point increase in cotinine is associated with a $2.6 \%$ increase in the probability that a child will be observed to be in less than excellent health. Comparing the predicted health gap between a child who has no exposure to passive smoking with a child with the highest level of exposure observed in the sample would lead to about a $15 \%$ difference in the probability of being in less than excellent health. Furthermore, the results presented for Model 3 in Table 3, show that while passive smoking is significantly detrimental to the health of both older and younger children, the effect is greater for the teenage sample. ${ }^{8}$

Finally, the results clearly highlight the fact that the inclusion of passive smoking measures has virtually no effect on the estimated income gradient, suggesting that this is not a major cause of the observed gradient in child health in England (see Currie et al., 2004; and Burgess et al., 2004).

\subsection{Robustness Check}

A potential problem with our estimates arises if the instruments we use to predict child passive smoking are endogenous i.e. there may be some unobserved health component common to both the child and the environment conducive to passive smoking. Then, the error term $v_{i h}$ in equation (1) will be correlated with the instruments $Z_{\text {ih }}$ in equation (2). The most likely contenders are health characteristics of the parents that impact on their smoking behaviour, resulting in greater observed and predicted passive smoking, but which are at the same time correlated with unobserved health characteristics of the child. For instance, there may be common intergenerational genes or psychological traits. While in the child health model we

\footnotetext{
${ }^{8}$ In this paper we have not made any attempt to test for the potential endogeneity of children's own smoking behaviour for the teenage sample. One example of how this could arise is if a child who smokes also regularly socialises with a 'bad' peer group. If this socialisation is associated with a higher probability of detrimental health shocks (e.g. due to fighting at school), which are unobserved in our data, this might lead us to overestimate the effect of own smoking on health. However, in our defence we note that the results for the older age group (which contains smokers) are very similar with respect to the effect of passive smoking as they are for the younger age group (which has no smokers).
} 
already include a large number of controls for parental health factors, it is a useful exercise to investigate whether there are some important unobserved parental health characteristics that could be responsible for our estimated effects of passive smoking on child health.

To test this possibility, we have extended the explanatory variables included in Model 3 to include a far wider range of parental health measures collected as part of the HSE nurse interview. The variables we include for both the mother and the father are:

1. The number of reported chronic health conditions (from the self-completion adult questionnaire);

2. Whether they are clinically obese (BMI $>29.9)$;

3. Whether they have high blood pressure (diastolic>89.9);

4. Whether they have either low or high haemoglobin (from blood test); and,

5. Whether they have either high or low ferritin (from blood test).

Health measures 2-5 are those typically taken by GPs as reliable underlying indicators of health status. When we include these additional parental health measures the coefficient on log cotinine is hardly effected, changing from $0.065(\mathrm{t}=3.51)$ in Model 3 to $0.064(\mathrm{t}=3.45) .{ }^{9}$ Given the comprehensiveness of these combined parental health measures, this provides some justification for the assumption that the instruments we used to overcome the issue of measurement error in our child passive smoking measure are uncorrelated with unobserved health factors codetermining the health of the child.

\subsection{Quantifying the Risk Factors}

We now turn to translating the health cost of risk factors for children's passive smoking into a monetary cost. We do this by posing the following question: By how much would family income have to rise to offset the reduction in child health caused by exposure to passive smoking through risk factor $k$ ? We refer this measure as an income equivalence scale. More formally, we define the equivalence income compensation $\Delta y$ (= shadow cost) as arising from an increase in passive smoking due to factor k changing from zero to $1, \delta_{k}$, for a reference child $j$ as:

\footnotetext{
${ }^{9}$ The full results of the exercise are available for the authors on request.
} 


$$
\begin{aligned}
& C H_{j}^{*}\left(\ln \left(P S_{j}\right), y_{j}\right)=C H_{j}^{*}\left(\ln \left(P S_{j}\right)+\delta_{k}, \ln \left(y_{j}+\Delta y_{j}\right)\right) \\
& \alpha \ln \left(y_{j}\right)+\gamma \ln \left(P S_{j}\right)=\alpha \ln \left(y_{j}+\Delta y_{j}\right)+\gamma\left(\ln \left(P S_{j}\right)+\delta_{k}\right) \\
& \rightarrow \Delta y_{j}=y_{j}\left(e^{-\frac{\gamma \delta_{k}}{\alpha}}-1\right)
\end{aligned}
$$

Here, the equivalent income has been defined as the income that keeps (latent) child health constant, which depends on the initial level of income in the household. ${ }^{10}$

In Table 4 we report our calculations, which use the coefficients from both the estimated passive smoking and general child health models discussed above, to explore the relative importance of various passive risk smoking factors. Column 1 in Table 4 shows the shadow value (=-shadow cost) of a change in each of the main risk factors by 1, while Column 2 gives the probability that the shadow value of any given factor is negative (i.e. it is a factor that would

be worth paying money to avoid) which is the same as the probability that $\gamma \delta_{k} / \alpha$ is positive. ${ }^{11}$ These probabilities are a measure of the statistical significance of the shadow values with probabilities close to 1 being the most important.

Each of these main risk factors, shown in Table 4, is potentially under the control of either the household or able to be influenced by a hypothetical policy-maker. These include direct choices, such as whether someone in the household smokes, as well as risk factors associated with being in a certain external environment as captured by the Index of Multiple Deprivations (DETR) score. As expected, the largest shadow values relate to the smoking behaviour of parents and carers. In particular, the income-health equivalent of a mother being a smoker is $£ 3446$ per year, and if she smokes 20 cigarettes a day, this increases to $£ 5,286$ per year (i.e. $£ 92 * 20+£ 3446$ ). The equivalent result for a father smoking 20 cigarettes per day is £3,631 per year. Large shadow prices are found for having other smokers (than mother and father) in the household and child carer who is a smoker.

An interesting finding relates to the level of deprivation in the area in which the child lives. Over and above the effect of parental and household characteristics, living in a relatively deprived area in England is associated with higher levels of child passive smoking, which in turn

\footnotetext{
${ }^{10}$ It is important to note here that we should not interpret negative shadow values as the cost of passive smoking in terms of utility or in terms of costs to the health service. The reported shadow values presume that child health is the outcome of ultimate concern and simply depict the equivalent amount of income that would have the same effect as a particular source of passive smoking on child health.

${ }^{11}$ We may note that the standard deviation of the shadow price is infinite because there is no bound on this ratio. Hence we report the joint probability of the effect of income on child health being positive, as well as the effect of the factor $k$ on child health via passive smoking to be negative.
} 
relates to poorer child health. For example, if we take an area with high relative deprivation (say a value of 50, from the observed range increasing in deprivation of 8-58), the income needed to compensate for the effect of passive smoking on child health would be $£ 1,595$ ( $£ 31.9 * 50)$ per year. In a worst case scenario where a child lives with both parents who smoke 20 cigarettes per day, also lives in a household where another household member is a smoker, additionally has a child carer who smokes and furthermore lives in the most deprived area, the income-health equivalence is $£ 15,755$ per year. That is a child would have to move to a household with an additional $£ 15,755$ per year of income to exactly offset the detrimental effect of passive smoking on their health.

In summary, these results show that the greatest risk to child health, via passive smoking, arises from the smoking behaviour of the mother, followed by that of the father, having a child carer who smokes and the presence of another smoker in the household. A final important influence to note is that children growing up in more economically and socially deprived areas (as captured by the Index of Multiple Deprivation) are exposed to a larger amount of passive smoking in their local environments.

\section{Conclusions}

In this paper we provide a detailed investigation of the factors that affect children's exposure to passive smoke, and the effect of such passive smoking on child health. Our main objective and contribution to the literature on passive smoking is to provide a new quantification of the cost of passive smoking for child health, which is useful to policy-makers when deciding upon the amount of resources that should be directed toward the problem. The data we use is drawn from the nationally representative Health Survey for England (HSE), which gives us a working sample of around 6,000 children for whom we can match parental and household characteristics. The particular advantage of the data is that a nurse, as part of a comprehensive household nurse interview, takes saliva swaps for children and the level of cotinine is then clinically established. Cotinine, which is a metabolite of nicotine, gives us a more objective measure of the extent that children are exposed to passive smoke than is often used. However, in our modelling strategy we allow for potential measurement error which might arise because cotinine values are sensitive to the metabolism of any given individual and because the concentration of cotinine is broken down in about 48 hours and thus depends heavily on transitory levels of passive smoking. The HSE data also provides detailed information on the smoking behaviour of parents and other household member, as well as the children themselves. 
We find evidence that parental smoking and the smoking behaviour of other household members and child carers are very strong predictors of child passive smoking levels. In fact, the explanatory variables we use account for about $50 \%$ of the total variation in observed cotinine levels. In particular, with the exception of a child's own smoking, the most important predictor of the amount of passive smoking that a child is exposed to is whether the mother smokes and how much she smokes, followed by the same characteristics for the father. Even after controlling for household income, parental employment, and both child and parental smoking, children with more educated parents have a significantly lower exposure to passive smoke. This finding points to the importance of health promotional campaigns that emphasise to the general adult (parental) population the risks of passive smoking for child health. Importantly, we also find that the external environment where a child lives plays a role in determining their exposure to passive smoke, with children residing in relatively deprived areas of England having the highest levels of exposure.

In terms of the effects of passive smoking on child health, we calculate that a one-log point increase in cotinine is associated with a $2.6 \%$ increase in the probability that a child will be observed to be in less than excellent health. This means that the health differential between children with no exposure to passive smoking and those with the highest levels in our sample is about $15.6 \%$. By comparing the effect of passive smoking with that of income on child health, we are able to calculate the total 'shadow cost' or income-equivalence of passive smoking for child health. In a worst case scenario, where a child is exposed to a very high level of passive smoking risk factors (e.g. both parents smoke a packet of 20 cigarettes per day, the child carer smokes, and the household resides in a highly deprived area), the shadow price is calculated to be around $£ 16,000$ (US\$30,000) per year. The income-equivalence of one extra cigarette smoked per day by a mother is $£ 92$, and a father is $£ 62$, per year.

A final finding of this study, directly relating to the recent literature that has focused on establishing the size of the gradient between family income and child health (e.g. Currie et al., 2002), is that comprehensively controlling for both a child's own smoking and their exposure to passive smoking does not explain away the income gradient.

In terms of public policy, the positive implication of this paper is that each of the main risk factors associated with passive smoking, namely the smoking behaviour of parents and carers, are amenable to public policy. Clearly a substantial change in the perception and behaviour of adults in the general population is required in order that smoking in the presence of children in the home environment becomes as much a social stigma as smoking in the workplace or in public buildings. 


\section{References}

Adair-Bischoff, CE. and Sauve, RS. (1998). Environmental tobacco smoke and middle ear disease in preschool-age children. Archives of Pediatric \& Adolescent Medicine, 152, pp. 127-133.

Adda, J. and Cornaglia, F. (2006a). Taxes, cigarette consumption, and smoking intensity. American Economic Review, forthcoming.

Adda, J. and Cornaglia, F. (2006b). The effect of taxes and bans on passive smoking. Centre for Economic Policy Research Discussion Paper no. 509, Australian National University, January.

ASH (2002). Passive Smoking: The Impact on Children. Available at www.ash.co.uk.

ASH (2005). Factsheet no. 8: Second-hand Smoke. Available at www.ash.co.uk.

Burgess, S., Propper, C. and Rigg, J. (2004). The impact of low-income on child health: Evidence from a birth cohort study. CMPO Working Paper Series no. 04/098, University of Bristol.

Burr, ML., Anderson, HR., Austin, JB., Harkins, LS., Kaur, B., and Strachan, DP. et al. (1999). Respiratory symptoms and home environment in children: A national survey. Thorax, 54, pp. 27-32.

Cameron, .A. and Williams, J. (2006). Is the Relationship between Socioeconomic Status and Health Stronger for Older Children in Developing Countries? Unpublished manuscript, University of Melbourne.

Case, A., Lubotsky, D. and Paxson, C. (2002). Economic status and health in childhood: The origins of the gradient. American Economic Review, 92, pp. 1308 -1334.

Cook, DG., Whincup, PH., Jarvis, MJ., Strachan, DP., Papcosta, O. and Bryan, A. (1994). Passive exposure to tobacco smoke in children aged 5-7 years: individual, family and community factors. British Medical Journal, 308, pp. 384-389.

Cook, DG. and Stachan, DP. (1999). Health effects of passive smoking - 10: Summary of effects of parental smoking on the respiratory health of children and implications for research. Thorax, 54, pp. 357-366.

Currie, J. and Stabile, M. (2003). Socioeconomic status and child health: Why is the relationship stronger for older children? American Economic Review, 93, pp. 1813-1823.

Currie, A., Shields, MA. and Wheatley Price, S. (2004). Is the child health / family income gradient universal? Evidence from England. IZA Discussion Paper no. 1328, Bonn.

EPA (1992). Respiratory Health Effects of Passive Smoking. United States Environmental Protection Agency.

EPA (1997). Health Effects of Exposure to Environmental Tobacco Smoke. California Environmental Protection Agency.

Eriksen, W. (2004). Do people who were passive smokers during childhood have increased risk of long-term work disability? European Journal of Public Health, 14, pp. 296-300.

Gilliland, FD, Li, YF. and Peters, JM. (2001). Effects of maternal smoking during pregnancy and environmental tobacco smoke on asthma and wheezing in children. American Journal of Respiratory and Critical Care Medicine, 163, pp. 429-436.

Gilliland, FD, Berhane, K., Islam, T., Wenten, M., Rappaport, E., Avol, E. et al. (2003). Environmental tobacco smoke and absenteeism related to respiratory illness in schoolchildren. American Journal of Epidemiology, 157, pp. 861-869.

Graham, H. and Power, C. (2004). Childhood Disadvantage and Adult Health: A Lifecourse Framework. London: NHS Health Development Agency (http://www.hda.nhs.uk/evidence).

Grossman, M. (1972). On the concept of health capital and the demand for health. Journal of Political Economy, 80, pp. 223-255. 
Hecht, SS., Ye, M., Carmella, SG., Fredrickson, A., Adgate, JL, Greaves, IA. et al. (2001). Metabolites of a tobacco-specific lung carcinogen in the urine of elementary school-aged children. Cancer Epidemiology Biomarkers \& Prevention, 10, pp. 1109-1116.

Idler, E. and Angel, R. (1990). Self-rated health and mortality in the NHANES. I. Epidemiologic follow-up study. American Journal of Public Health, vol. 80, pp. 446-452.

Idler, E. and Benysmini, Y. (1997). Self-reported health and mortality: A review of twentyseven community studies. Journal of Health and Social Behavior, vol. 38, pp. 21-37.

Idler, E. and Kasl, S. (1995). Self-rating of health: Do they also predict change in functional ability? Journal of Gerontology: Social Sciences, vol. 508, pp. S344-S353.

Iles, K, Poplawski, NK. and Couper, RTL. (2001). Passive exposure to tobacco smoke and bacterial meningitis. Journal of Paediatrics and Child Health, 37, pp. 388-391.

Jarvis, MJ., Goddard, E., Higgins, V., Feyerabend, C., Bryant, A. and Cook, D. (2000). Children's exposure to passive smoking in England since the 1980s: Cotinine evidence from population surveys. British Medical Journal, 321, pp. 343-345.

Lieu, J.E. and Feinstein. A.R. (2002). The effect of gestational and passive smoke exposure on ear infections in children.” Archives of Pediatric \& Adolescent Medicine, 156, pp. 147154.

Li, JS., Peat, JK., Xuan, W. and Berry, G. (1999). Meta-analysis on the association between environmental tobacco smoke (ETS) exposure and the prevalence of lower respiratory tract infection in early childhood. Pediatric Pulmonology, 27, pp. 5-13.

Li, YF. and Peters, JM. (2001). Effects of maternal smoking during pregnancy and environmental tobacco smoke on asthma and wheezing in children. American Journal of Respiratory and Critical Care Medicine, 163, pp. 429-436.

Mannino, DM., Moorman, J., Kingsley, B., Rose, D., Repace, J. (2001). Health effects related to environmental tobacco smoke exposure in children in the United States. Archives of Pediatric \& Adolescent Medicine, 155, pp. 36-41.

Mannino, DM., Homa, DM. and Redd, SC. (2002). Involuntary smoking and asthma severity in children: data from the Third National Health and Nutrition Examination Survey. Chest, 122, pp. 409-415.

SCOTH (1998). Report of the Scientific Committee on Tobacco and Health, London: The Stationary Office.

SCOTH (2004). Update of evidence of health effects of second-hand smoke. Report of the Scientific Committee on Tobacco and Health, London: Department of Health.

Shields, MA. and Wheatley Price, S. (2005). Exploring the economic and social determinants of psychological well-being and perceived social support in England. Journal of the Royal Statistical Society, Series A, 168, pp. 513-538.

Sprosten, K. and Primatesta, P. (2003). Health Survey for England 2002 - The Health of Children and Young People. Volume 3: methodology and documentation. London: The Stationary Office.

US Surgeon General (2006). The Health Consequences of Involuntary Exposure to Tobacco Smoke: A Report of the Surgeon General. Available on the Surgeon General's Web site at: surgeongeneral.gov/library/secondhandsmoke.

Van Doorslaer, E. and Gerdtham, U. (2003) Does inequality in self-assessed health predict inequality in survival by income? Evidence from Swedish data, Social Science and Medicine, vol. 57, pp. 1621-1629.

WHO (1999). International consultation on environmental tobacco smoke (ETS) and child health. Geneva: World Health Organisation (Tobacco Free Initiative).

Windham, G.C., Eaton, A. Hopkins, B. (1999). Evidence for an association between environmental tobacco smoke exposure and birthweight: A meta-analysis and new data. Pediatric Perinatal Epidemiology, 13, pp. 35-37. 
FIGURE 1: Child Cotinine Level by Annual Household Income

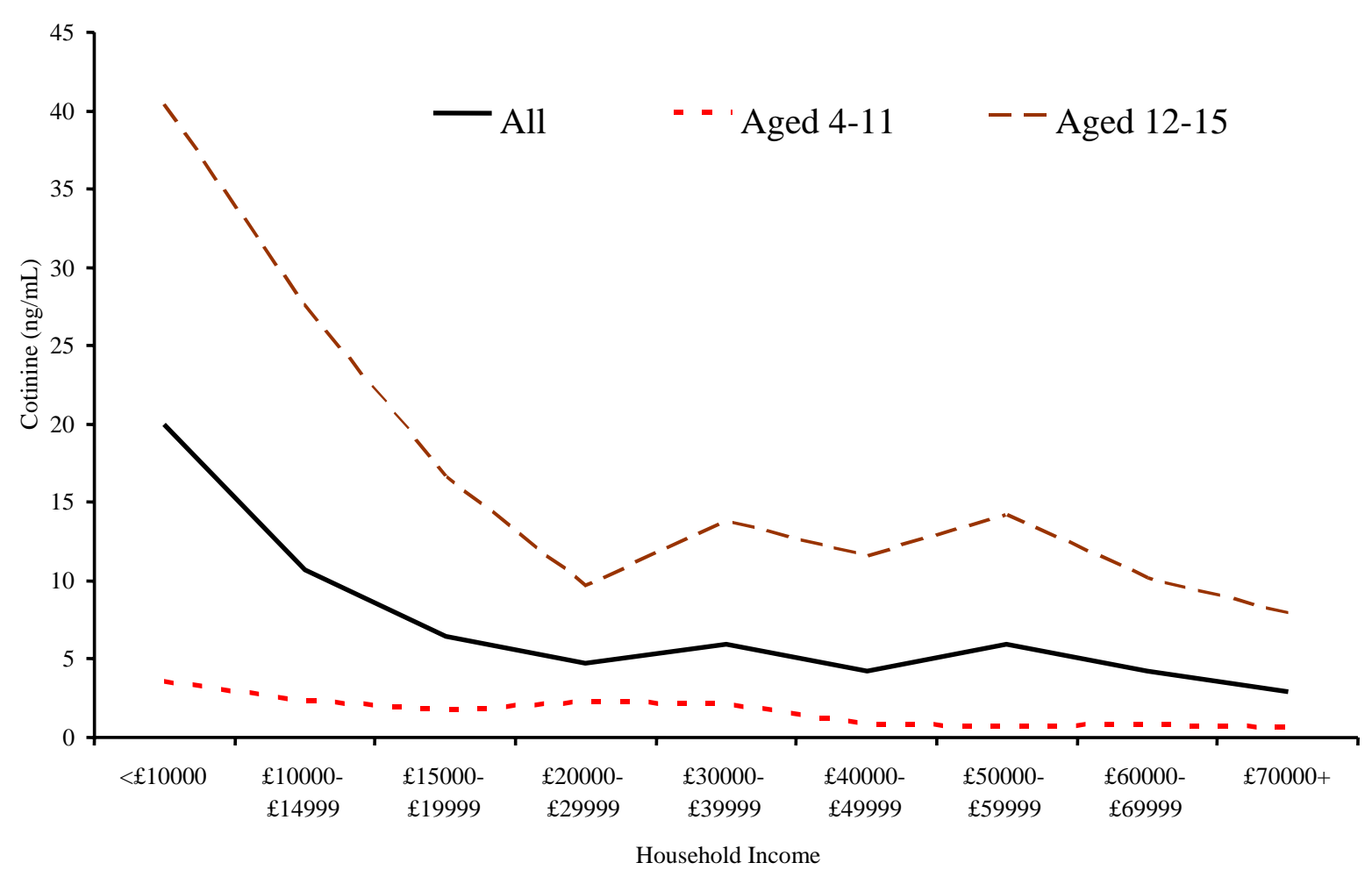

FIGURE 2: Child Health Status by Cotinine Level

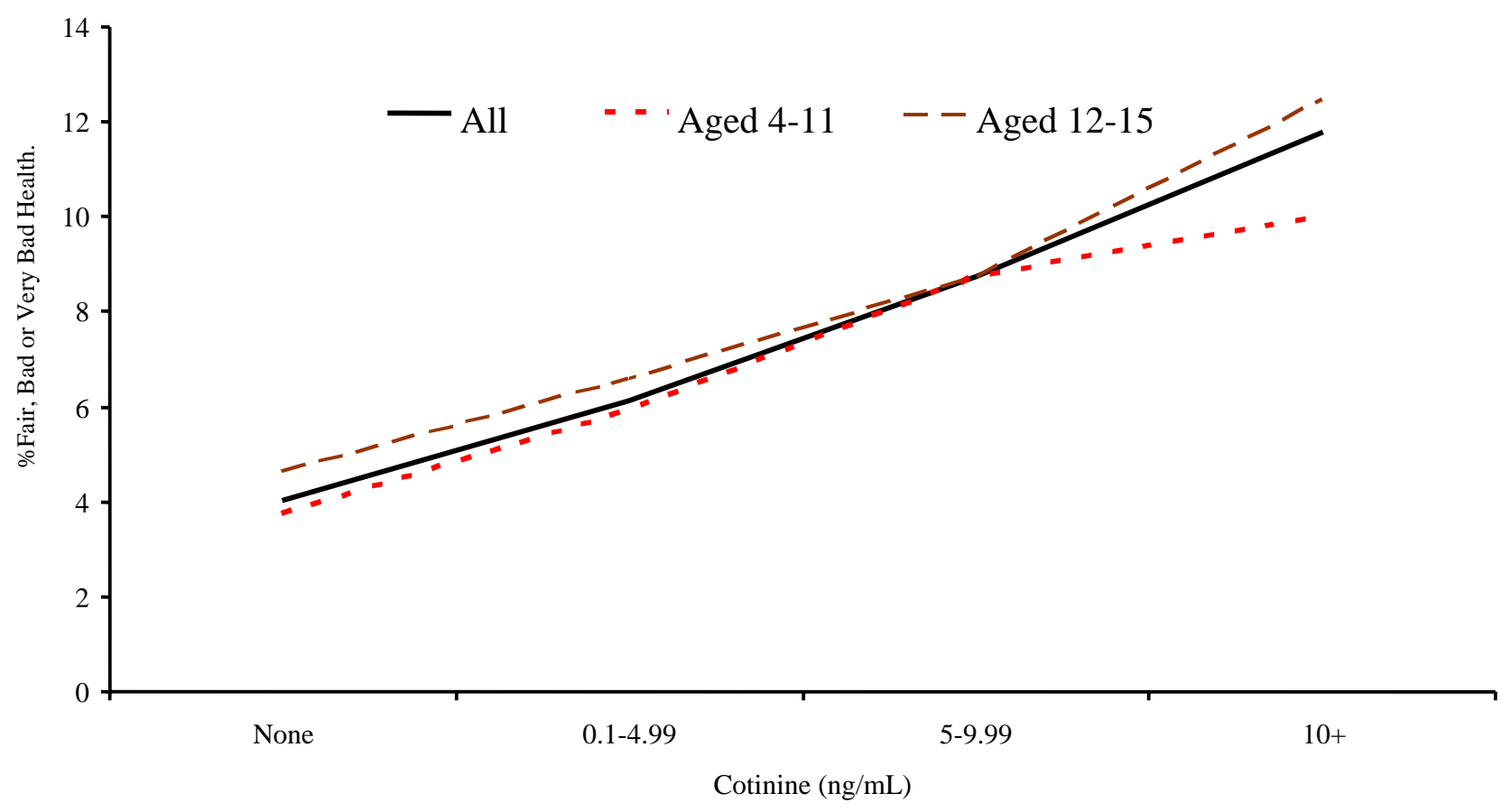


TABLE 1:

First Stage Tobit Models of Child Cotinine Level by Age

\begin{tabular}{|c|c|c|c|c|c|c|}
\hline \multirow[t]{2}{*}{ Sample } & \multicolumn{2}{|c|}{ Aged 4-15 } & \multicolumn{2}{|c|}{ Aged 4-11 } & \multicolumn{2}{|c|}{ Aged 12-15 } \\
\hline & $\boldsymbol{\beta}$ & $t$ & $\boldsymbol{\beta}$ & $t$ & $\boldsymbol{\beta}$ & $t$ \\
\hline Age dummies & YES & YES & YES & YES & YES & YES \\
\hline Male & -0.026 & -0.76 & -0.083 & -2.53 & 0.077 & 1.00 \\
\hline Black & -0.291 & -2.13 & -0.277 & -2.07 & -0.435 & -1.50 \\
\hline Asian & -0.346 & -3.03 & -0.254 & -2.24 & -0.709 & -3.04 \\
\hline Other ethnicity & -0.099 & -0.88 & -0.116 & -1.07 & -0.175 & -0.70 \\
\hline Log real annual household income & -0.100 & -2.95 & -0.064 & -1.89 & -0.183 & -2.63 \\
\hline Child currently smokes & 2.920 & 20.01 & - & - & 3.142 & 15.83 \\
\hline Child - amount smokes & 0.025 & 5.25 & - & - & 0.019 & 3.11 \\
\hline Mother currently smokes & 0.783 & 9.34 & 0.722 & 8.92 & 0.962 & 5.34 \\
\hline Mother - amount smokes & 0.016 & 3.52 & 0.018 & 3.94 & 0.008 & 0.78 \\
\hline Mother's cotinine level & 0.001 & 7.57 & 0.001 & 7.83 & 0.001 & 3.45 \\
\hline Father currently smokes & 0.497 & 4.97 & 0.413 & 4.08 & 0.491 & 2.47 \\
\hline Father - amount smokes & 0.011 & 2.40 & 0.017 & 3.60 & 0.008 & 0.90 \\
\hline Father's cotinine level & 0.000 & 2.38 & 0.001 & 2.56 & 0.000 & 0.66 \\
\hline Other smoker in household & 0.531 & 9.39 & 0.429 & 7.28 & 0.713 & 6.53 \\
\hline Other non-smoker in household & -0.043 & -2.05 & -0.030 & -1.44 & -0.060 & -1.38 \\
\hline Child carer currently smokes & 0.528 & 9.72 & 0.581 & 11.20 & 0.405 & 2.35 \\
\hline Grandfather (on father’s side) smoked & 0.013 & 0.26 & 0.003 & 0.06 & 0.043 & 0.41 \\
\hline Grandmother (on father's side) smoked & 0.040 & 0.73 & 0.021 & 0.40 & 0.053 & 0.47 \\
\hline Grandfather (on mother's side) smoked & -0.020 & -0.47 & -0.108 & -2.58 & 0.124 & 1.37 \\
\hline Grandmother (on mother's side) smoked & 0.027 & 0.59 & 0.085 & 1.90 & -0.071 & -0.75 \\
\hline Father not in household & 0.612 & 1.02 & 0.753 & 1.40 & 0.363 & 0.19 \\
\hline Mother not in household & 0.378 & 1.56 & 0.182 & 0.70 & -0.113 & -0.22 \\
\hline Age of father & -0.006 & -1.34 & 0.000 & 0.01 & -0.012 & -1.32 \\
\hline Age of mother & 0.000 & -0.03 & -0.002 & -0.57 & -0.005 & -0.48 \\
\hline Father has a degree level or equivalent qualification & -0.275 & -3.36 & -0.297 & -3.60 & -0.279 & -1.71 \\
\hline Mother has a degree level or equivalent qualification & -0.367 & -4.70 & -0.317 & -4.05 & -0.358 & -2.27 \\
\hline Father has an 'A' level or equivalent qualification & -0.197 & -2.89 & -0.204 & -2.97 & -0.176 & -1.31 \\
\hline Mother has an ' $A$ ' level or equivalent qualification & -0.267 & -4.37 & -0.237 & -3.95 & -0.225 & -1.78 \\
\hline Father has an 'O' level or equivalent qualification & -0.056 & -0.83 & -0.045 & -0.65 & -0.045 & -0.33 \\
\hline Mother has an ' $\mathrm{O}$ ' level or equivalent qualification & -0.185 & -3.57 & -0.174 & -3.37 & -0.146 & -1.39 \\
\hline
\end{tabular}


TABLE 1: (Continued)

\begin{tabular}{l|cc|cc|cc}
\hline Father is unemployed & 0.158 & 1.01 & 0.129 & 0.81 & 0.207 & 0.69 \\
Mother is unemployed & 0.057 & 0.44 & 0.070 & 0.56 & -0.031 & -0.11 \\
Father is not in the labour force & 0.179 & 1.63 & 0.061 & 0.53 & 0.395 & 1.89 \\
Mother is not in the labour force & 0.050 & 0.99 & 0.070 & 1.43 & -0.001 & -0.01 \\
Father has a long-term limiting illness & -0.101 & -1.17 & -0.099 & -1.12 & -0.066 & -0.39 \\
Mother has a long-term limiting illness & 0.060 & 0.81 & 0.108 & 1.42 & -0.057 & -0.39 \\
\hline Lives in a suburban location & 0.021 & 0.35 & -0.063 & -1.09 & 0.156 & 1.30 \\
Lives in a rural location & -0.070 & -0.99 & -0.170 & -2.44 & 0.092 & 0.64 \\
Index of Multiple Deprivation & 0.006 & 2.25 & 0.005 & 2.19 & 0.003 & 0.59 \\
Region dummies & YES & YES & YES & YES & YES & YES \\
Father drinks on 5 or more days & 0.109 & 1.84 & 0.120 & 2.02 & 0.079 & 0.66 \\
Mother drinks on 5 or more days & 0.032 & 0.50 & -0.006 & -0.09 & 0.071 & 0.54 \\
\hline Constant & 0.339 & 0.85 & 0.032 & 0.08 & 0.866 & 1.01 \\
\hline Sigma u (Household random error) & 0.874 & 31.92 & 0.787 & 30.91 & 0.905 & 8.61 \\
Sigma e & 1.078 & 55.82 & 0.817 & 40.59 & 1.482 & 22.75 \\
\hline \% Total Variance accounted for by XB & $49.2 \%$ & & $49.9 \%$ & & $41.2 \%$ & \\
\% of Total Unexplained Variation accounted for by U & $39.5 \%$ & & $48.2 \%$ & & $28.2 \%$ & \\
\hline Log Likelihood & -10421 & & -6255 & & -3885 & \\
\hline Sample & 6679 & & 4460 & & 2219 & \\
\hline
\end{tabular}

Notes: Models also control for household income missing, father's (mother's) smoking information missing, father's (mother's) cotinine level missing, father (mother) in household but did not respond to survey, father's (mother's) drinking information missing, and year of survey. 
TABLE 2:

Ordered Probit Estimates of the Impact of Passive Smoking (PS) on Child Health Status

\begin{tabular}{|c|c|c|c|c|c|c|}
\hline \multirow{3}{*}{ Sample (All children aged $4-15)$} & \multicolumn{2}{|c|}{ Model 1} & \multicolumn{2}{|c|}{ Model 2} & \multicolumn{2}{|c|}{ Model 3} \\
\hline & \multicolumn{2}{|c|}{ No Control for PS } & \multicolumn{2}{|c|}{ Raw PS } & \multicolumn{2}{|c|}{ Instrumented PS } \\
\hline & $\beta$ & $t$ & $\beta$ & $t$ & $\beta$ & $t$ \\
\hline Log cotinine level & - & - & 0.032 & 2.96 & 0.065 & 3.51 \\
\hline Age dummies & YES & YES & YES & YES & YES & YES \\
\hline Male & -0.038 & -1.29 & -0.036 & -1.23 & -0.034 & -1.18 \\
\hline Black & 0.253 & 2.24 & 0.274 & 2.41 & 0.300 & 2.61 \\
\hline Asian & 0.141 & 1.50 & 0.164 & 1.74 & 0.191 & 2.01 \\
\hline Other ethnicity & 0.178 & 1.87 & 0.180 & 1.89 & 0.183 & 1.94 \\
\hline Log real annual household income & -0.109 & -3.68 & -0.103 & -3.46 & -0.095 & -3.15 \\
\hline Child currently smokes & 0.349 & 2.78 & 0.250 & 1.94 & 0.337 & 2.67 \\
\hline Child - amount smokes & 0.005 & 1.01 & 0.004 & 0.83 & 0.005 & 0.98 \\
\hline Father not in household & -0.194 & -1.07 & -0.190 & -1.05 & -0.186 & -1.02 \\
\hline Mother not in household & -0.069 & -0.31 & 0.021 & 0.11 & 0.041 & 0.20 \\
\hline Age of father & -0.002 & -0.59 & -0.002 & -0.52 & -0.001 & -0.41 \\
\hline Age of mother & -0.001 & -0.27 & -0.000 & -0.14 & 0.000 & 0.02 \\
\hline Father has a degree level or equivalent qualification & -0.028 & -0.40 & -0.008 & -0.12 & 0.019 & 0.27 \\
\hline Mother has a degree level or equivalent qualification & -0.329 & -4.89 & -0.309 & -4.56 & -0.278 & -4.02 \\
\hline Father has an 'A' level or equivalent qualification & -0.100 & -1.69 & -0.083 & -1.42 & -0.064 & -1.08 \\
\hline Mother has an 'A' level or equivalent qualification & -0.180 & -3.48 & -0.162 & -3.11 & -0.139 & -2.61 \\
\hline Father has an 'O' level or equivalent qualification & -0.026 & -0.44 & -0.016 & -0.28 & -0.005 & -0.08 \\
\hline Mother has an 'O' level or equivalent qualification & -0.143 & -3.30 & -0.132 & -3.02 & -0.117 & -2.65 \\
\hline Father is unemployed & -0.095 & -0.70 & -0.111 & -0.81 & -0.133 & -0.97 \\
\hline Mother is unemployed & -0.047 & -0.41 & -0.054 & -0.50 & -0.068 & -0.62 \\
\hline Father is not in the labour force & 0.200 & 2.19 & 0.188 & 2.05 & 0.173 & 1.88 \\
\hline Mother is not in the labour force & 0.040 & 0.91 & 0.036 & 0.83 & 0.032 & 0.72 \\
\hline Father has a long-term limiting illness & 0.140 & 1.92 & 0.144 & 1.98 & 0.149 & 2.06 \\
\hline Mother has a long-term limiting illness & -0.009 & -0.14 & -0.010 & -0.16 & -0.012 & -0.19 \\
\hline Lives in a suburban location & -0.041 & -0.82 & -0.043 & -0.85 & -0.044 & -0.87 \\
\hline Lives in a rural location & -0.108 & -1.78 & -0.105 & -1.73 & -0.103 & -1.69 \\
\hline Index of Multiple Deprivation & -0.000 & -0.22 & -0.001 & -0.29 & -0.001 & -0.39 \\
\hline Region dummies & YES & YES & YES & YES & YES & YES \\
\hline Father drinks on 5 or more days & 0.047 & 0.91 & 0.042 & 0.82 & 0.037 & 0.70 \\
\hline Mother drinks on 5 or more days & 0.032 & 0.59 & 0.029 & 0.52 & 0.023 & 0.42 \\
\hline Log Likelihood & -5738 & & -5733 & & -5731 & \\
\hline Sample & 6679 & & 6679 & & 6679 & \\
\hline
\end{tabular}

Notes: Models also control for household income missing, father's (mother's) smoking information missing, father's (mother's) cotinine level missing, father (mother) in household but did not respond to survey, father's (mother's) drinking information missing, log of household size and year of survey. 
TABLE 3:

Ordered Probit Estimates of the Impact of Passive Smoking (PS) on Child Health Status by Age

\begin{tabular}{|c|c|c|c|c|}
\hline \multirow[t]{3}{*}{ Sample } & \multicolumn{2}{|c|}{ Aged 4-11 } & \multicolumn{2}{|c|}{ Aged 12-15 } \\
\hline & \multicolumn{2}{|c|}{ Instrumented PS } & \multicolumn{2}{|c|}{ Instrumented PS } \\
\hline & $\beta$ & $t$ & $\beta$ & $t$ \\
\hline Log cotinine level & 0.056 & 2.54 & 0.072 & 2.37 \\
\hline Age dummies & YES & YES & YES & YES \\
\hline Male & 0.047 & 1.28 & -0.201 & -4.00 \\
\hline Black & 0.331 & 2.54 & 0.228 & 1.09 \\
\hline Asian & 0.303 & 2.66 & -0.073 & -0.47 \\
\hline Other ethnicity & 0.264 & 2.51 & 0.014 & 0.08 \\
\hline Log real annual household income & -0.114 & -3.20 & -0.064 & -1.38 \\
\hline Child currently smokes & - & - & 0.344 & 2.49 \\
\hline Child - amount smokes & - & - & 0.006 & 1.13 \\
\hline Father not in household & -0.170 & -0.80 & -0.253 & -0.81 \\
\hline Mother not in household & -0.123 & -0.50 & 0.456 & 1.36 \\
\hline Age of father & -0.002 & -0.55 & -0.002 & -0.28 \\
\hline Age of mother & -0.004 & -0.79 & 0.010 & 1.52 \\
\hline Father has a degree level or equivalent qualification & -0.005 & -0.06 & 0.057 & 0.51 \\
\hline Mother has a degree level or equivalent qualification & -0.331 & -3.97 & -0.185 & -1.73 \\
\hline Father has an 'A' level or equivalent qualification & -0.127 & -1.71 & 0.070 & 0.79 \\
\hline Mother has an 'A' level or equivalent qualification & -0.192 & -3.03 & -0.055 & -0.64 \\
\hline Father has an ' $\mathrm{O}$ ' level or equivalent qualification & 0.004 & 0.06 & -0.039 & -0.44 \\
\hline Mother has an 'O' level or equivalent qualification & -0.166 & -3.11 & -0.028 & -0.40 \\
\hline Father is unemployed & -0.064 & -0.37 & -0.242 & -1.19 \\
\hline Mother is unemployed & -0.025 & -0.20 & -0.148 & -0.81 \\
\hline Father is not in the labour force & 0.151 & 1.28 & 0.230 & 1.62 \\
\hline Mother is not in the labour force & 0.046 & 0.89 & -0.023 & -0.32 \\
\hline Father has a long-term limiting illness & 0.157 & 1.72 & 0.132 & 1.25 \\
\hline Mother has a long-term limiting illness & -0.028 & -0.34 & 0.0244 & 0.26 \\
\hline Lives in a suburban location & -0.074 & -0.92 & 0.029 & 0.37 \\
\hline Lives in a rural location & -0.061 & -0.82 & -0.182 & -1.94 \\
\hline Index of Multiple Deprivation & -0.001 & -0.34 & 0.000 & 0.03 \\
\hline Region dummies & YES & YES & YES & YES \\
\hline Father drinks on 5 or more days & -0.001 & -0.01 & 0.118 & 1.52 \\
\hline Mother drinks on 5 or more days & 0.061 & 0.89 & -0.045 & -0.53 \\
\hline Log Likelihood & -3739 & & -1952 & \\
\hline Sample & 4460 & & 2219 & \\
\hline
\end{tabular}

Notes: Models also control for household income missing, father's (mother's) smoking information missing, father's (mother's) cotinine level missing, father (mother) in household but did not respond to survey, father's (mother's) drinking information missing, log of household size and year of survey. 
TABLE 4:

Shadow Value of Passive Smoking Risk Factors

\begin{tabular}{|c|c|c|}
\hline & Column 1 & Column 2 \\
\hline Main Risk Factors & $\begin{array}{c}\text { Raw } \\
\text { Shadow } \\
\text { Price (£) }\end{array}$ & $\begin{array}{c}\text { Probability } \\
\text { Negative } \\
\text { Shadow } \\
\text { Price }\end{array}$ \\
\hline Mother currently smokes & $\begin{array}{l}-3446.3 \\
\end{array}$ & 0.998 \\
\hline Mother - amount currently smokes & -92.0 & 0.998 \\
\hline Mother's cotinine level & -8.2 & 0.998 \\
\hline Father currently smokes & -2397.0 & 0.998 \\
\hline Father - amount currently smokes & -61.7 & 0.983 \\
\hline Father's cotinine level & -2.8 & 0.984 \\
\hline Other current smoker in household & -2466.9 & 0.998 \\
\hline Child carer currently smokes & -2520.6 & 0.998 \\
\hline Grandfather (on father’s side) smoked & -65.2 & 0.551 \\
\hline Grandmother (on father's side) smoked & -230.4 & 0.649 \\
\hline Grandfather (on mother's side) smoked & 108.9 & 0.346 \\
\hline Grandmother (on mother's side) smoked & 151.2 & 0.556 \\
\hline Index of Multiple Deprivation & -31.9 & 0.975 \\
\hline Father drinks on 5 or more days & -588.3 & 0.929 \\
\hline Mother drinks on 5 or more days & -184.1 & 0.611 \\
\hline
\end{tabular}

